\title{
Overwintering of Frankliniella fusca (Thysanoptera: Thripidae) on Winter Annual Weeds Infected with Tomato spotted wilt virus and Patterns of Virus Movement Between Susceptible Weed Hosts
}

\author{
R. L. Groves, J. F. Walgenbach, J. W. Moyer, and G. G. Kennedy
}

First, second, and fourth authors: North Carolina State University, Department of Entomology, Raleigh 27695; and third author: North Carolina State University, Department of Plant Pathology, Raleigh 27695.

Accepted for publication 23 May 2001.

\begin{abstract}
Groves, R. L., Walgenbach, J. F., Moyer, J. W., and Kennedy, G. G. 2001. Overwintering of Frankliniella fusca (Thysanoptera: Thripidae) on winter annual weeds infected with Tomato spotted wilt virus and patterns of virus movement between susceptible weed hosts. Phytopathology 91:891-899.

Overwintering of tobacco thrips, Frankliniella fusca, was investigated on common winter annual host plants infected with Tomato spotted wilt virus (TSWV). Populations of tobacco thrips produced on TSWVinfected plants did not differ from those produced on healthy plants, whereas populations varied greatly among host plant species. The mean per plant populations of $F$. fusca averaged 401, 162, and 10 thrips per plant on Stellaria media, Scleranthus annuus, and Sonchus asper, respectively, during peak abundance in May. Adult F. fusca collected from plant hosts were predominately brachypterous throughout the winter and early spring, but macropterous forms predominated in late spring. Weed hosts varied in their ability to serve as overwintering sources of TSWV inoculum. Following the initial infection by TSWV in October 1997, 75\% of Scleranthus annuus and Stellaria media retained infection over the winter and spring season, whereas only 17\% of Sonchus asper plants remained infected throughout the same interval. Mortality of TSWV-infected Sonchus asper plants exceeded 25\%, but mortality of infected Stellaria media and Scleranthus annuus did not exceed $8 \%$.

lowest on Sonchus asper (2\%). Very few viruliferous $F$. fusca were recovered from soil samples collected below infected wild host plants. Vegetative growth stages of Stellaria media, Sonchus asper, and Ranunculus sardous were more susceptible to F. fusca transmission of TSWV than flowering growth stages, whereas both growth stages of Scleranthus annuus were equally susceptible. In a field study to monitor the spatial and temporal patterns of virus movement from a central source of TSWV-infected Stellaria media to adjacent plots of $R$. sardous, the incidence of infection in $R$. sardous plots increased from $<1 \%$ in March to $>42 \%$ in June 1999. Infection levels in the Stellaria media inoculum source remained high throughout the experiment, averaging nearly 80\% until June 1999 when all Stellaria media plants had senesced. Dispersal of TSWV from the inoculum source extended to the limits of the experimental plot $(>37 \mathrm{~m})$. Significant directional patterns of TSWV spread to the $R$. sardous plots were detected in April and May but not in June. $R$. sardous infections were detected as early as March and April, suggesting that overwintering inoculum levels in an area can increase rapidly during the spring in susceptible weed hosts prior to planting of susceptible crops. This increase in the abundance of TSWV inoculum sources occurs at a time when vector populations are increasing rapidly. The spread of TSWV among weeds in the spring serves to bridge the period when overwintered inoculum sources decline and susceptible crops are planted.
\end{abstract} TSWV transmission by thrips produced on infected plants was greatest on Stellaria media (18\%), intermediate on Scleranthus annuus (6\%), and
Additional keyword: F. occidentalis.
In the southeastern United States, Tomato spotted wilt virus (TSWV) is a serious pathogen affecting a variety of agronomic, vegetable, and ornamental crops (4,22). Since the virus was first detected in the southeastern region (15), the incidence of TSWV has risen to destructive levels in peanut (Arachis hypogaea L.), pepper (Capsicum annuum L.), tomato (Lycopersicon esculentum Mill.), and tobacco (Nicotiana tabacum L.) $(17,18,27)$.

TSWV is acquired by first instar thrips feeding on infected host plant material. Virus replication occurs in the thrips and results in persistent transmission over the life of an infected adult (22). TSWV is transmitted by at least eight species of thrips (23), with tobacco thrips, Frankliniella fusca Hinds, and western flower thrips, F. occidentalis (Pergande), considered potentially important vectors of this disease in the southeastern United States (26, 29,30). Although the onion thrips, Thrips tabaci Lindeman, regularly occurs in this region, recent studies have indicated that

Corresponding author: R. L. Groves; E-mail address: Russ_Groves@ncsu.edu

Publication no. P-2001-0702-02R

This article is in the public domain and not copyrightable. It may be freely reprinted with customary crediting of the source. The American Phytopathological Society, 2001. most populations are not competent vectors of TSWV (22). Based on the temporal occurrence of populations in the field (15) and their presence on overwintering, noncrop host plants (12), F. fusca is considered to be the major vector responsible for primary spread of TSWV to susceptible crops in North Carolina.

Chamberlain et al. (7) suggested that overwintering thrips harbor TSWV infection. They reported that up to $10 \%$ of macropterous adults, $6 \%$ of brachypterous adults, and $<1 \%$ of overwintering immature $F$. fusca tested positive for infection of TSWV by serological assays, but they were unable to confirm the presence of TSWV in overwintering, diapausing $F$. fusca. In another study, Barbour and Brandenburg (1) concluded that transmission of TSWV by postdiapause $F$. fusca was negligible.

As is the case with other insect-transmitted plant viruses, wild plant hosts likely contribute to the spread of TSWV by serving as both a reservoir for virus infection and as a reproductive host for the vectors (13). Numerous field and laboratory studies have identified weed species that serve as overwintering hosts of the major vectors of TSWV $(1-3,8,9,12,14,19,24,27,29,33)$. Additionally, many field surveys and laboratory transmission experiments have identified noncrop hosts of TSWV $(2,5,10,11,20,21,25,28$, 32). However, the development of thrips populations throughout the winter on TSWV-infected winter weed hosts and the sub- 
sequent spread of TSWV from infected winter weeds is not well understood. This study was conducted to determine the ability of F. fusca to overwinter on TSWV-infected and healthy winter annual weed hosts that are common in the southeastern United States, and to describe the temporal and spatial patterns of virus spread in the spring from a known overwintered source.

\section{MATERIALS AND METHODS}

Experimental insects. $F$. fusca were obtained from a colony maintained on green bean (Phaseolus vulgaris L.) pods in an enclosed laboratory chamber maintained at $24^{\circ} \mathrm{C}, 65 \%$ relative humidity (RH), and 14/10 h (light/dark) photoperiod. The virusfree status of the colony was verified periodically by testing randomly sampled adult thrips by enzyme-linked immunosorbent assay (ELISA) and an antiserum against the nonstructural protein of the S RNA of TSWV. The laboratory colony originated from insects collected in peanut from the Peanut Belt Research Station (Lewiston, NC) in 1995.

Virus material. A single isolate of TSWV, TSWV-RG2, collected in 1995 from burley tobacco, N. tabacum 'B21', was used in all experiments. The isolate was maintained in Emilia sonchifolia (L.) DC. ex Wight growing in cylindrical cages (14-cm diameter $\times 30 \mathrm{~cm}$ high) constructed from clear plastic $(5-\mathrm{mm}$ Vivak plastic; AIN Plastics, Greensboro, NC) and covered with BedBug 110 screening (Greenthumb Group, Downer's Grove, IL). Infected plants were held in a greenhouse under conditions of $28 / 20^{\circ} \mathrm{C}$ (light/dark) and a $14 / 10 \mathrm{~h}$ (light/dark) photoperiod. Every 12 weeks the virus was transmitted to healthy $E$. sonchifolia by $F$. fusca. In all cases, plants were classified as healthy or TSWVinfected by double antibody sandwich (DAS)-ELISA (Agdia Inc., Elkhart, IN) with antisera to the $\mathrm{N}$ protein.

Vector and virus overwintering experiment. The ability of $F$. fusca and TSWV to overwinter on or in three winter annual weed species was investigated in small-plot field experiments at North Carolina State University, Raleigh. Common chickweed (Stellaria media (L.) Cyrillo), knawel (Scleranthus annuus L.), and spinyleaved sowthistle (Sonchus asper L.) were germinated in a virusfree greenhouse under insect-proof cages. When plants reached the four to six true leaf stage, 160 plants of each weed species
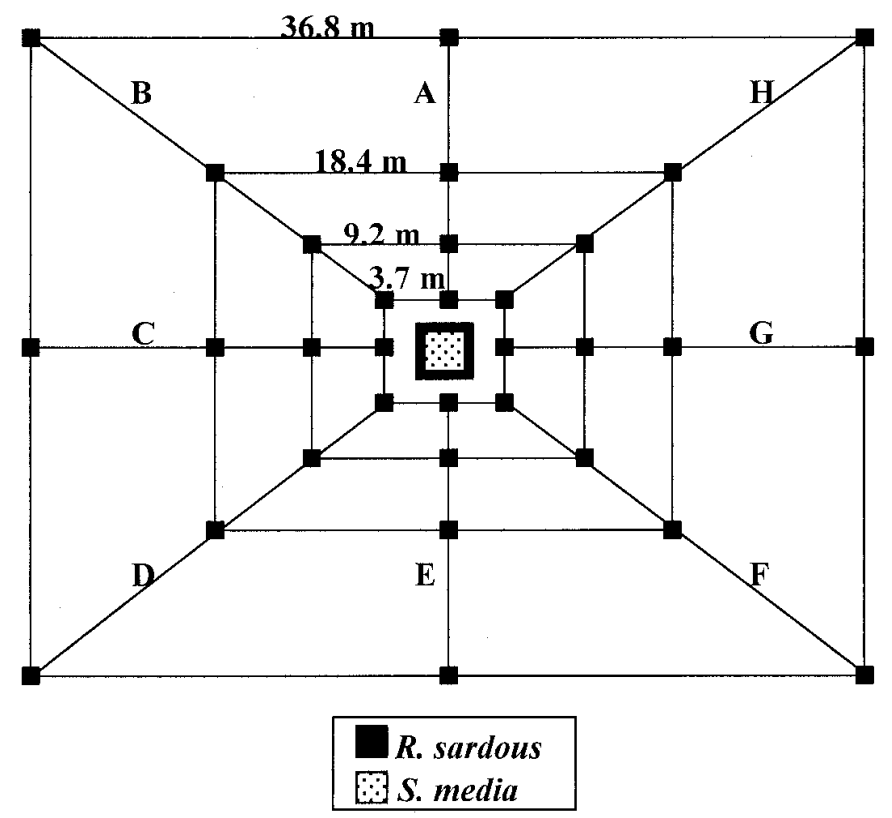

Fig. 1. Experimental plot layout with Tomato spotted wilt virus-infected Stellaria media source plants and Ranunculus sardous planted in small, subplots ( $\boldsymbol{\square})$ at five distances $(1.5$ to $36.8 \mathrm{~m}$ ) from the virus source along eight different radians (A to $\mathrm{H}$ ) originating at the center source. were transplanted into black plastic pots $(15-\mathrm{cm}$ diameter $\times 20 \mathrm{~cm}$ high) and again placed under insect-proof cages (14-cm diameter $\times$ $30 \mathrm{~cm}$ high). One week later, 80 plants from each of the three weed species were sap-inoculated with TSWV-RG2 from infected $N$. benthamiana Domin; the remaining 80 plants were not inoculated and served as uninfected control plants. The TSWV inoculum preparation consisted of sap extract of TSWV-infected $N$. benthamiana mixed 1:10 in inoculation buffer containing $0.01 \mathrm{M}$ Tris buffer ( $\mathrm{pH} 7.8), 5.7 \mathrm{mM}$ cysteine hydrochloride, and $1 \mathrm{mM}$ sodium sulfite. Inoculum was maintained in an ice bath throughout the inoculation procedure. Following inoculation, plants were recaged for 14 days and tested by DAS-ELISA to confirm systemic infection.

Sixty systemically infected, symptomless plants and 60 healthy plants of each weed species were transplanted into field plots in a randomized complete block design with five experimental blocks containing each species and infection combination. All plants of each weed species were individually caged under cylindrical, clear-plastic, insect-proof cages $(25-\mathrm{cm}$ diameter $\times 40 \mathrm{~cm}$ high). Virus-free, adult female $F$. fusca were aspirated into $2.5-\mathrm{ml}$ disposable Pasteur pipettes (10 thrips per pipette) that were sealed at each end by Parafilm to prevent escape. Thrips were released from pipettes onto the individually caged weeds. The experimental plot was planted, infested, and caged in October 1997 and subsequently sampled to assess retention of TSWV infection and thrips populations at $6,12,16$, and 20 weeks posttransplant.

On each sample date, 10 randomly selected TSWV-infected and 10 uninfected plants (two from each of five experimental blocks) were cut at the soil surface and set inside 5.6-liter white plastic containers (Venture Packaging Inc., Monroeville, $\mathrm{OH}$ ) containing a Phaseolus vulgaris pod. The containers were covered with screened lids (BedBug 110) and placed in environmental chambers maintained at $25^{\circ} \mathrm{C}, 20 \% \mathrm{RH}$, and a $14 / 10 \mathrm{~h}$ (light/dark) photoperiod for $72 \mathrm{~h}$. As the weeds desiccated, thrips concentrated on the bean pod, which remained succulent. Within 3 days after the plants had fully desiccated, all adult and immature $F$. fusca on the bean pods were collected and counted. Adult thrips were placed into 5-dram glass vials containing 70\% EtOH and classified by sex and wingform. Immature thrips were reared to the adult stage by transferring them to fresh bean pods in meshcovered (BedBug 110) 474-ml clear plastic cups at $24^{\circ} \mathrm{C}, 65 \%$ $\mathrm{RH}$, and a photoperiod of $14 / 10 \mathrm{~h}$ (light/dark). After emerging as adults, up to 25 thrips from TSWV-infected weed hosts were held for an additional $48 \mathrm{~h}$ on the bean pod and individually subjected to a petunia leaf disk assay (31) to determine their ability to transmit TSWV. Circular leaf disks $\left(1 \mathrm{~cm}^{2}\right)$ of Petunia hybrida 'Celebrity Blue' were used in the bioassay. The presence of TSWV in suspected lesions on the petunia disks was confirmed by DAS-ELISA. ELISA assays were scored on a THERMOmax microtiter plate reader (Molecular Devices Corp., Menlo Park, CA) at a transmission wavelength of $405 \mathrm{~nm}$. Leaf disks were considered TSWV-infected if the optical density was greater than the mean plus 3 standard deviations of the noninfected controls of the same plant species.

On each sample date after plants were cut and collected, the surface layer of soil $(7.4 \mathrm{~cm})$ under each cage was removed and placed into 5.6-liter plastic containers. A bean pod was added to each container to collect emerging $F$. fusca. Bean pods were collected and replaced every 2 days over a period of 22 days to maintain fresh host material for emerging thrips. Adult thrips emerging from soil in which noninfected weed hosts had been growing were transferred to $70 \% \mathrm{EtOH}$ and classified by sex and wingform. Up to 25 adult thrips collected from soil in which TSWV-infected plants were grown were individually subjected to the petunia leaf disk bioassay and classified by sex and wingform.

Plant growth stage experiment. Small-plot field and greenhouse experiments were conducted to compare the relative susceptibility of vegetative (four to six true leaf stage) and flowering 
(first flower) stage Stellaria media, Scleranthus annuus, Sonchus asper, and Ranunculus sardous Crantz with transmission of TSWV by F. fusca. For field studies, the two growth stages were replicated three times in a randomized complete block design with 20 plants per growth stage in each block. The same experimental design was used in a greenhouse experiment to compare the susceptibility of vegetative and flowering stage $R$. sardous to transmission of TSWV by $F$. fusca. Plants were started from seed under insect-proof cages in a virus-free greenhouse and were transplanted to the field 5 days before release of thrips.

Neonate $F$. fusca were allowed a 48-h acquisition access period on excised TSWV-infected E. sonchifolia foliage. Larvae were placed on bean pods and reared to the adult stage. In the field and greenhouse experiments, 2-day-old adults were aspirated from the bean pods into pipettes (10 thrips per pipette) and released onto experimental plants growing in insect-proof cages. These adults were allowed an inoculation access period of $48 \mathrm{~h}$, after which all plants were treated with a foliar application of imidacloprid $(7.1 \mathrm{~g}$ a.i. per 1,000 plants) to kill the thrips and their progeny. After 21 days, plants were tested for systemic infection by DAS-ELISA.

Spatial and temporal patterns of TSWV spread. Two hundred greenhouse-grown Stellaria media seedlings were sap-inoculated with the TSWV-RG2 isolate in a virus-free greenhouse. Inoculated plants remained uncaged in the greenhouse for 21 days after which 150 plants, confirmed by DAS-ELISA to be systemically infected by TSWV, were infested with adult female $F$. fusca and $F$. occidentalis. On 2 October 1998, the plants were transplanted in a plot $(2.3 \times 2.3 \mathrm{~m})$ in the center of a 0.42 -ha field on the Lower Coastal Plain Tobacco Research Station, Kinston, NC. Healthy $R$. sardous seedlings were also transplanted into a series of plots within the 0.42-ha field. The plot layout for this test is illustrated in Figure 1. TSWV-infected Stellaria media was planted in the center of the field. The $R$. sardous plots were planted at five distances from the center of the Stellaria media plot (1.5, 3.7, 9.2, 18.4 , and $36.8 \mathrm{~m}$ ) along eight equally spaced radians (A-H) corresponding to $306,261,216,171,126,81,36$, and $351^{\circ}$ azimuth. Each $R$. sardous plot $\left(\approx 1 \mathrm{~m}^{2}\right)$, except those at the 1.5 -m distance, consisted of six equally spaced rows of five plants per row, whereas subplots at the $1.5-\mathrm{m}$ distance contained $20 \mathrm{R}$. sardous plants in two rows of 10 plants per row $\left(\approx 0.7 \mathrm{~m}^{2}\right)$ planted parallel to the perimeter of the Stellaria media plot. The ground between plots was maintained free of vegetation by cultivation. Three sides of the experimental site were bordered by fallow fields containing infestations of winter annual weed species, whereas the fourth side was bordered by wheat (Triticum aestivum L.) planted in late September 1998. Fallow fields were disked in early April 1999 in preparation for planting corn (Zea mays L.).

Leaf samples from 50 randomly selected Stellaria media plants were removed at monthly intervals from January through June 1999 and subjected to DAS-ELISA to assess the incidence of TSWV infection. Half of the total foliage from 10 randomly selected plants was also removed at monthly intervals, placed in 5.6-liter plastic containers with fine-mesh screen lids, and returned to the laboratory. Adult thrips were recovered, as described previously, and identified to species, sex, and wingform. All immature thrips collected were transferred to bean pods and reared to adult. Up to 25 of the newly emerged adult thrips per plant were individually subjected to a petunia leaf disk assay to determine their ability to transmit TSWV. Beginning in March 1999 and continuing at monthly intervals through June, the incidence of TSWV was assessed in all $R$. sardous plots. Three leaves from different positions along the stem of each $R$. sardous plant in each plot were collected. These samples were grouped with comparable samples collected from other plants in the same row within a plot, resulting in six sets of 15 leaves per plot. ELISA was conducted on the grouped samples to determine TSWV infection. In the perimeter $R$. sardous plots $(1.5 \mathrm{~m})$ adjacent to the Stellaria media, only four sets of 15 leaves per plot were collected on each sample date.
At distances of $3.7,9.2,18.4,36.8$, and $45 \mathrm{~m}$ from the plot center and along radial directions 306, 216, 126, and 36, aerial thrips traps were positioned to sample the number and composition of dispersing thrips in the air above the experimental plot (Fig. 1 ). Traps at $45 \mathrm{~m}$ were located $\approx 10 \mathrm{~m}$ outside of the experimental plot in adjacent fields. Each trap consisted of a cylindrical section (3.8 $\mathrm{cm}$ long $\times 2.5$-cm diameter) of yellow PVC pipe wrapped with Tanglefoot-coated plastic wrap (Great Lakes IPM, Vestaburg, MI) and fastened $1 \mathrm{~m}$ above the soil surface on a wooden dowel. Aerial traps were collected and replaced every 2 weeks over the course of the experiment from October 1998 through June 1999. Plastic wrap was cut from the traps and examined under a binocular stereoscope $(\times 128)$ to determine the species composition and the number of thrips recovered per sample interval.

Finally, in an attempt to quantify TSWV infection in nearby susceptible crops, six individual tobacco fields within a $3-\mathrm{km}$ radius of the experimental plot were surveyed to estimate TSWV incidence. Four of the six fields surveyed were planted to N. tabacum 'NC71', whereas the remaining two fields were planted to $N$. tabacum 'K-326'. In all six fields, plants in 10 randomly selected transects of 100 plants were visually scored for TSWV infection based on the presence of symptoms. Fields were surveyed in June and July 1999, and a random subsample of foliage from 10 TSWV symptomatic plants was subjected to DAS-ELISA to verify infections.

Statistical analysis. All analyses were completed using SAS, version 7 (SAS Institute, Cary, NC). Comparisons of mean thrips populations and levels of infection among TSWV-infected and healthy wild host plants were conducted using analysis of variance (ANOVA) (PROC GLM; LSMEANS). In these experiments, thrips counts were log-transformed, whereas percent infection data were arcsine square root transformed for normalization. In experiments comparing susceptibility of plant growth stages to inoculation of TSWV by $F$. fusca, percent transmission data were arcsine square root transformed for normality and subjected to ANOVA (PROC GLM), and means were separated by $F$ tests $(\alpha=0.05)$. In the experiment examining temporal and spatial characteristics of TSWV spread, disease incidence and aerial trap capture data were subjected to a repeated measures ANOVA (PROC GLM) to test for effects of distance and direction relative to the inoculum source. Percent infection data were arcsine square root transformed, whereas aerial trap data were log-transformed to normalize variance. All means presented in tables and figures were back-transformed.

\section{RESULTS}

Vector and virus overwintering experiment. In order to determine how effectively TSWV could overwinter in noncrop host plants, retention of infection throughout the winter season was measured in the three experimental weed species. Mean TSWV infection levels differed among the three wild host species over the course of the experiment, resulting in a significant plant speciesdate interaction $(F=3.89$; df $=8$ and $105 ; P=0.0234)$ (Fig. 2).

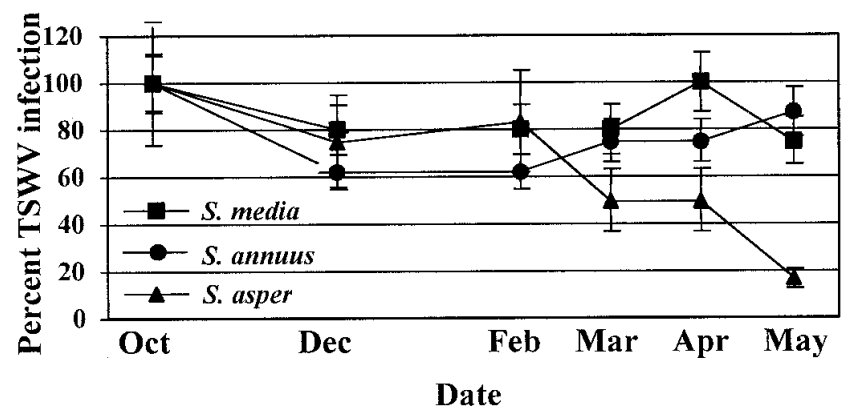

Fig. 2. Mean percent retention of Tomato spotted wilt virus (TSWV) infection in winter annual weeds throughout the virus and vector overwintering experiment, Raleigh, NC. 
Over the 24-week experiment, the incidence of infection in Stellaria media remained high ( $\geq 75 \%$ of plants), indicated by ELISA. The incidence of TSWV ELISA-positive Scleranthus annuus initially declined to $62.5 \%$ during the winter, but increased to $88 \%$ by May. In contrast, the incidence of TSWV ELISApositive Sonchus asper was similar to both Stellaria media and Sonchus asper through mid-February, but declined to a low of $17 \%$ in May. Mean percent infection values reported for each species were calculated based on the number of living plants remaining on each sample date. TSWV infection was not detected in the healthy control plants.

In addition to declining rates of infection within TSWV-infected Sonchus asper throughout the experiment, considerable plant mortality was observed among infected Sonchus asper plants. Of a total of 60 infected Sonchus asper plants at the beginning of the experiment, approximately 8, 17, and 23\% died by March, April, and May, respectively. In contrast, $<4 \%$ of the 60 healthy Sonchus asper control plants died during the experiment. Likewise, $<8 \%$ of the plants in both the inoculated and healthy Stellaria media and Scleranthus annuus plants died during the experiment. Other than the increased mortality in Sonchus asper plants, overt symptoms of TSWV infection were not observed in any of the TSWVinoculated weeds.

The suitability of virus-infected plants versus healthy plants as reproductive hosts for $F$. fusca was also measured throughout the experiment. Infection status of the host plant did not significantly influence the mean abundance of total $F$. fusca $(F=0.63$; df $=1$ and $240 ; P=0.4521)$ or of either adult $(F=0.75$; df $=1$ and 240 ; $P=0.3874)$ or immature $(F=0.29 ; \mathrm{df}=1$ and $240 ; P=0.5893) F$. fusca, evidenced by the lack of a significant main effect of infection status and by the absence of significant interaction effects involving infection status of the host plant on abundance of adults
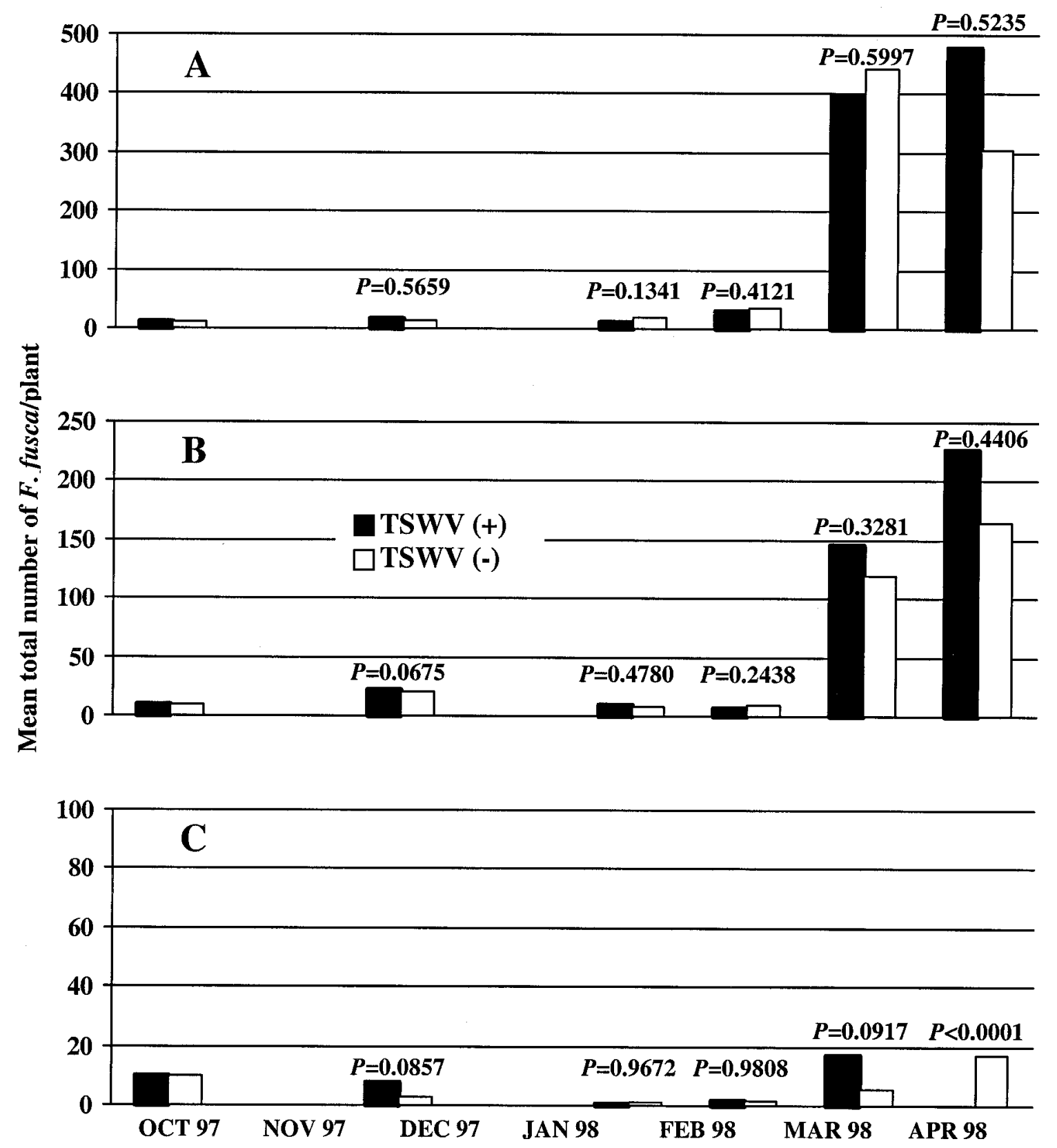

Date

Fig. 3. Mean total Frankliniella fusca collected from A, Stellaria media, B, Schleranthus annuus, and C, Sonchus asper. Probabilities of differences between means from Tomato spotted wilt virus (TSWV)-infected and healthy weed species by date are shown above columns $(\alpha=0.05)$. 
and immatures (Fig. 3). Similarly, the proportion of immature $F$. fusca in the total population did not vary between TSWV-infected and healthy plants $(F=0.32 ; \mathrm{df}=1$ and $240 ; P=0.4783$; and $F=$ $0.29 ; \mathrm{df}=1$ and $240 ; P=0.3985$, respectively).

Although infection status did not impact $F$. fusca populations, the number of thrips recovered from plants varied greatly among plant species over time, indicated by a highly significant speciesdate interaction for both adult $(F=12.64$; $\mathrm{df}=8$ and $240 ; P<$ $0.0001)$ and immature $(F=5.83 ; \mathrm{df}=8$ and $240 ; P<0.0001) F$. fusca averaged across TSWV treatment status (Fig. 3). Stellaria media consistently produced the greatest total number of $F$. fusca over the course of the experiment. Populations of $F$. fusca were intermediate on Scleranthus annuus and were lowest on Sonchus asper. The species-date interaction can be attributed to a dramatic late-season increase in populations of F. fusca on Stellaria media and Scleranthus annuus, but not on Sonchus asper.

Although plant species significantly affected the populations of F. fusca recovered from plants, the proportion of macropterous (winged) adult F. fusca was not affected by plant species or TSWV infection, indicated by the absence of significant plant species $(F=1.19 ; \mathrm{df}=2$ and $163 ; P=0.3076)$ and infection status $(F=$ $0.77 ; \mathrm{df}=1$ and $163 ; P=0.7704)$ main and interaction effect $(F=$ 0.33 ; df $=2$ and $163 ; P=0.7196)$. However, the proportion of adult macropterous $F$. fusca differed significantly among sample

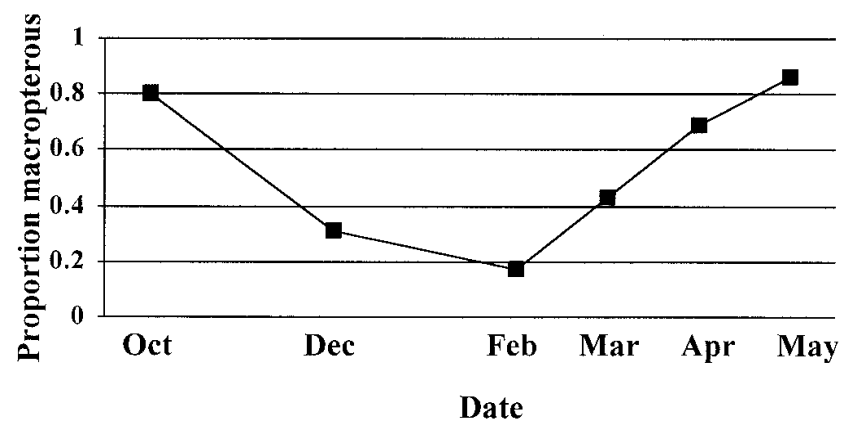

Fig. 4. Proportion of adult macropterous Frankliniella fusca collected over time from Stellaria media, Schleranthus annuus, and Sonchus asper. dates $(F=7.07$; df $=5$ and $8 ; P=0.0022)$ averaged across the three host plant species (Fig. 4). Brachypterous (reduced or nonwinged) adults predominated through the winter and into very early spring, whereas macropterous adults predominated in the fall and spring sample dates.

Similarly, no significant main or interaction effects on sex ratio were observed for infection status of host $(F=0.46$; $\mathrm{df}=1$ and 8; $P=0.8776)$, sample date $(F=1.28$; df $=5$ and $8 ; P=0.3541)$, or plant species $(F=1.58 ; \mathrm{df}=2$ and $8 ; P=0.5701)$. The proportion of adult female $F$. fusca averaged $0.97,0.99,0.96,0.90$, and 0.83 in the December, February, March, April, and May samples, respectively.

To further compare plant species as more or less suitable overwintering inoculum sources, estimates of the number of potentially viruliferous $F$. fusca generated on each host were obtained with a petunia leaf disk assay. The proportion of $F$. fusca collected as immatures that transmitted TSWV as adults utilizing this assay differed significantly among the three weed species $(F=13.52$; df $=$ 2 and $8 ; P=0.0027$ ). A significantly greater proportion of $F$. fusca transmitted TSWV from Stellaria media than from either Scleranthus annuus or Sonchus asper (Table 1). During April and May, thrips from Scleranthus annuus transmitted TSWV more frequently than thrips from Sonchus asper. The highest level of virus transmission occurred in March for Sonchus asper (5.6\%), April for Scleranthus annuus (10.2\%), and in May for Stellaria media (34.7\%).

The opportunity for TSWV to overwinter within diapausing or quiescent $F$. fusca was investigated by collecting thrips from soil samples under infected host plants and subsequently determining the proportion of infected thrips recovered. Thirty-six $F$. fusca were recovered from soil samples: 17 in March, 14 in April, and 5 in May; and 16 of these were recovered from soil under TSWVinfected plants. Twenty four were macropterous females and 12 were brachypterous males. Two females (12.5\%), collected in May, transmitted TSWV in the petunia leaf disk assay: one was collected from soil under an infected Stellaria media and the other from soil under Sonchus asper.

Plant growth stage experiment. Differential susceptibility among plant developmental stages of susceptible host plants was investigated to further qualify the ability of a weed species to serve as a source for spread of TSWV. Plant growth stage did not

TABLE 1. Mean \pm standard error percentage of Frankliniella fusca immatures collected from Tomato spotted wilt virus (TSWV)-infected winter annual weed species, which transmitted TSWV to Petunia hybrida 'Celebrity Blue' leaf disks as adults ${ }^{\mathrm{z}}$

\begin{tabular}{|c|c|c|c|c|c|}
\hline$\underline{\text { Plant species }}$ & December 1997 & February 1998 & March 1998 & April 1998 & May 1998 \\
\hline Stellaria media & $\begin{array}{c}6.95 \pm 0.03 \mathrm{a} \\
(N=119)\end{array}$ & $\begin{array}{c}7.50 \pm 0.04 \mathrm{a} \\
(N=47)\end{array}$ & $\begin{array}{c}18.1 \pm 0.06 \mathrm{a} \\
(N=69)\end{array}$ & $\begin{array}{c}20.1 \pm 0.03 \mathrm{a} \\
(N=228)\end{array}$ & $\begin{array}{c}34.7 \pm 0.06 \mathrm{a} \\
(N=173)\end{array}$ \\
\hline Scleranthus anпииs & $\begin{array}{c}1.58 \pm 0.01 \mathrm{~b} \\
(N=147)\end{array}$ & $\begin{array}{c}1.00 \pm 0.01 \mathrm{~b} \\
(N=52)\end{array}$ & $\begin{array}{c}7.71 \pm 0.04 \mathrm{~b} \\
(N=26)\end{array}$ & $\begin{array}{c}10.2 \pm 0.04 \mathrm{~b} \\
(N=159)\end{array}$ & $\begin{array}{c}8.45 \pm 0.02 \mathrm{~b} \\
(N=117)\end{array}$ \\
\hline Sonchus asper & $\begin{array}{c}1.09 \pm 0.01 \mathrm{~b} \\
(N=50)\end{array}$ & $\begin{array}{c}0.00 \pm 0.00 \mathrm{~b} \\
(N=1)\end{array}$ & $\begin{array}{c}5.55 \pm 0.06 \mathrm{~b} \\
(N=6)\end{array}$ & $\begin{array}{c}2.80 \pm 0.02 \mathrm{c} \\
(N=69)\end{array}$ & $\begin{array}{l}\cdots \\
\cdots\end{array}$ \\
\hline
\end{tabular}

${ }^{\mathrm{z}}$ Means within a column followed by the same letter are not significantly different by PROC GLM, LSMEANS $(\alpha=0.05)$. Optical densities at $405 \mathrm{~nm}$ ranged from 1.132 to 3.981 in TSWV-infected petunia leaf disks and from 0.063 to 0.084 in healthy leaf disks.

TABLE 2. Effect of plant growth on incidence of infection by Tomato spotted wilt virus (TSWV) following a 48-h inoculation access period by viruliferous Frankliniella fusca

\begin{tabular}{|c|c|c|c|c|}
\hline \multirow[b]{2}{*}{ Plant growth stage } & \multicolumn{4}{|c|}{ Plant species ${ }^{z}$} \\
\hline & Ranunculus sardous & Stellaria media & Schleranthus annuus & Sonchus asper \\
\hline Vegetative & $83.0 \pm 5.5 \mathrm{a}$ & $50.0 \pm 6.6 \mathrm{a}$ & $11.6 \pm 4.9 \mathrm{a}$ & $30.5 \pm 6.1 \mathrm{a}$ \\
\hline Four to eight leaf stage & $(N=45)$ & $(N=60)$ & $(N=60)$ & $(N=60)$ \\
\hline Flowering & $65.2 \pm 7.1 \mathrm{a}$ & $17.0 \pm 5.2 \mathrm{~b}$ & $6.8 \pm 3.3 \mathrm{a}$ & $9.4 \pm 4.1 \mathrm{~b}$ \\
\hline First flower stage & $(N=45)$ & $(N=58)$ & $(N=60)$ & $(N=54)$ \\
\hline
\end{tabular}

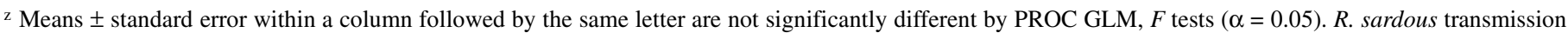
assays were conducted as greenhouse experiments, whereas Stellaria media, Schleranthus annuus, and Sonchus asper assays were conducted as small-plot field experiments. Optical densities at $405 \mathrm{~nm}$ ranged from 2.248 to 4.112 for infected vegetative stage plants and from 1.767 to 4.072 in flowering plants, whereas healthy plants ranged from 0.061 to 0.107 and 0.086 to 0.112 in vegetative and flowering plants, respectively, across all plant species tested. 
significantly affect the incidence of TSWV infection of $R$. sardous following inoculation by $F$. fusca $(F=4.69$; df $=1$ and $2 ; P=$ 0.1628 ), although the incidence of transmission to $R$. sardous tended to be lower in flowering than vegetative stage plants in the greenhouse experiment (Table 2). In the field cage experiment, transmission of TSWV to Scleranthus annuus tended to be low and did not differ significantly between vegetative and flowering stages $(F=1.57 ; \mathrm{df}=1$ and $2 ; P=0.3374)$, although transmission to flowering plants tended to be less than to vegetative plants. In contrast, transmission to vegetative plants was significantly greater than to flowering plants for both Stellaria media $(F=44.16$; $\mathrm{df}=$ 1 and $2 ; P=0.0219)$ and Sonchus asper $(F=142.45 ; \mathrm{df}=1$ and 2 ; $P=0.0069)$.
Spatial and temporal patterns of TSWV spread. In a separate experiment to monitor the overwintering success of TSWV in a susceptible weed host (Stellaria media), the spatial and temporal patterns of virus movement into nearby $R$. sardous plots was also monitored. Mean incidence of ELISA-detectable TSWV infection in the Stellaria media source plot differed significantly among dates $(F=11.25$; df $=5$ and $138 ; P<0.0001)$, but remained relatively high until the final sample date in June when all Stellaria media source plants had senesced (Fig. 5A). TSWV incidence in the $R$. sardous plots differed significantly among dates $(F=54.04$; df $=3$ and $84 ; P<0.0001$ ) (Fig. 5A). No TSWV infections were detected in the $R$. sardous plots prior to March 1999 when mean infection averaged only $0.5 \%$. Incidence of TSWV-infected $R$.

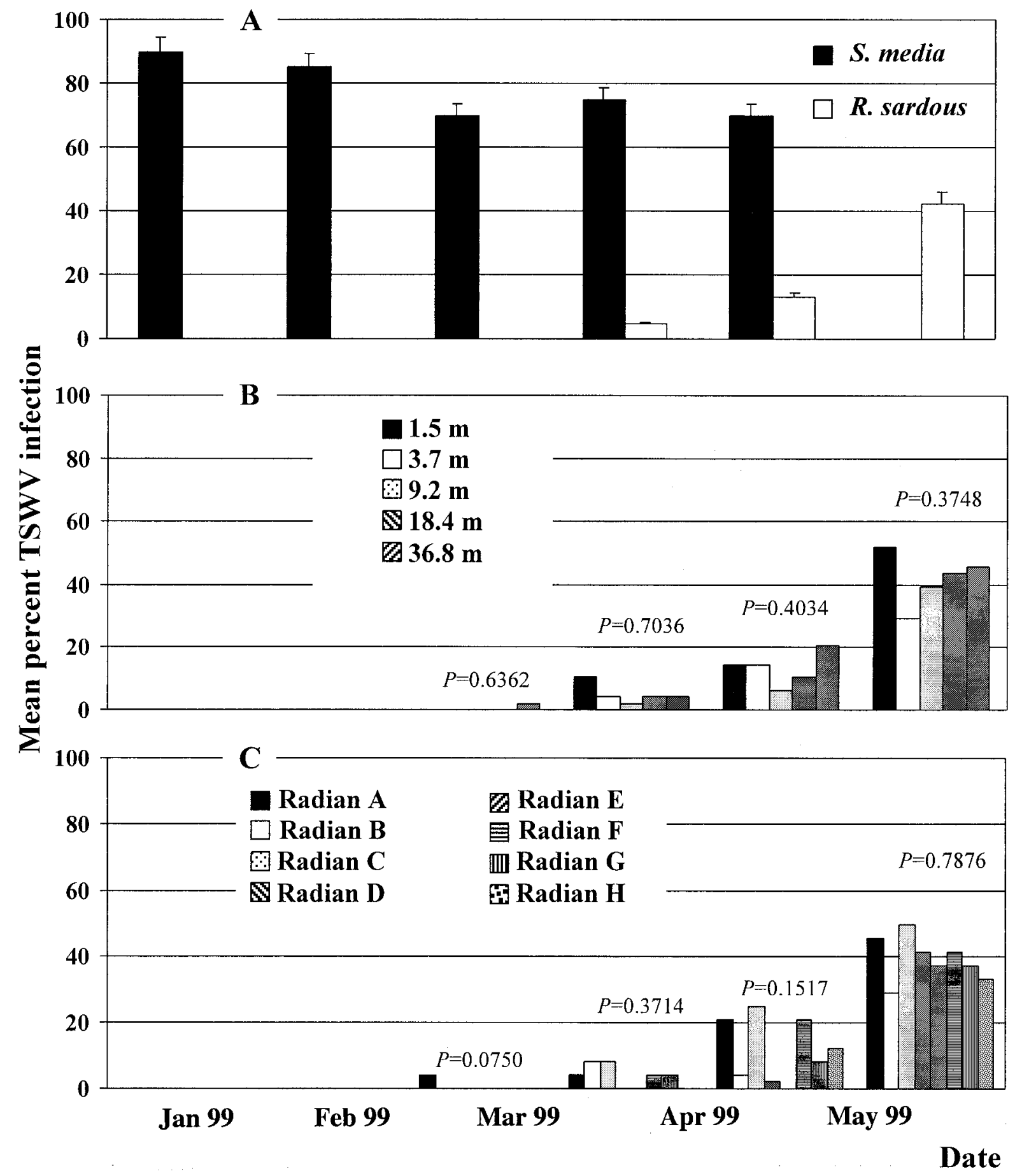

Fig. 5. A, Percent Tomato spotted wilt virus (TSWV) infection of Stellaria media source plants and Ranunculus sardous plots averaged over five distances and eight radial directions; $\mathbf{B}$, percent TSWV infection of $R$. sardous subplots by distance averaged over eight radial directions; and $\mathbf{B}$, by radial direction averaged over the five distances. Probabilities of differences among infection levels are shown above columns $(\alpha=0.05)$. 
sardous plants increased in April, May, and June samples and averaged 4.6, 13.2, and 42.1\%, respectively. Neither distance $(F=$ $0.89 ; \mathrm{df}=4$ and $28 ; P=0.4820)$ nor direction $(F=0.46 ; \mathrm{df}=7$ and 28; $P=0.8540$ ) main effects were significant (Fig. 5B and $\mathrm{C}$, respectively). Similarly, neither date-distance $(F=0.70 ; \mathrm{df}=12$ and $84 ; P=0.7509)$ nor date-direction $(F=0.53 ; \mathrm{df}=21$ and $84 ; P=$ 0.9512 ) interactions were significant. However, when repeated measures analysis was re-executed, excluding the last sample date, sample date-direction interaction was significant $(F=2.99 ; \mathrm{df}=6$ and $24 ; P=0.0252)$. The June sample date, which had the highest percentage of TSWV-infected plants, was omitted to reduce potential effects of secondary spread among or within the $R$. sardous plots from the analysis. Results of this analysis indicate that in both April and May 1999, TSWV incidence was significantly lower (0.0 and $5.5 \%$, respectively) in $R$. sardous plots along paired radians D-E (mean azimuth $\left.=149^{\circ}\right)($ Fig. 1) compared with the three remaining paired radians, B-C, F-G, and $\mathrm{H}-\mathrm{A}$, in which infection rates were 9.1, 7.3, and 6.8\%, respectively, in April, and $16.4,14.5$, and $16.4 \%$, respectively, in May.

To assess populations of potential TSWV vectors developing on the infected source plants (Stellaria media), thrips were collected from a portion of infected plants and subjected to the petunia leaf disk assay. Total numbers (adult + immature) of both $F$. fusca and $F$. occidentalis recovered from TSWV inoculum source plants (Stellaria media) varied significantly over the course of the experiment $(F=3.85$; df $=4$ and $95 ; P=0.0061$; and $F=10.69$; df $=4$ and 95; $P<0.0001$, respectively) (Table 3 ). No data were recorded in June 1999 because all Stellaria media plants had senesced. Thrips populations were highest in April, when they coincidentally averaged 59.5 thrips per plant for both $F$. fusca and F. occidentalis. In contrast, the proportion of immature thrips recovered from the Stellaria media source plants, which transmitted TSWV to petunia leaf disks as adults, did not differ significantly among sample dates for either $F$. fusca $(F=1.21$; df $=4$ and 95; $P=0.3132)$ or $F$. occidentalis $(F=4.95 ; \mathrm{df}=4$ and $95 ; P=$ 0.2321 ). When averaged across the five sample dates (January to May 1999), $7.9 \pm 1.9 \%$ of $F$. fusca and $5.5 \pm 1.5 \%$ of F. occidentalis transmitted TSWV to petunia leaf disks.

Dispersal of potential TSWV vectors from the inoculum source was monitored by aerial sticky traps placed at varying distances away from the TSWV source. The mean number of $F$. fusca captured on aerial sticky traps was influenced by a significant date-distance interaction $(F=2.96$; $\mathrm{df}=20$ and $60 ; P=0.0006)$. Approximately equal numbers of $F$. fusca were captured at all distances from the inoculum source during April, whereas the greatest numbers were caught close to the inoculum source during May but furthest from the inoculum source in June (Fig. 6). Over the course of the experiment, the number of $F$. fusca captured did not vary among the four directions, indicated by the absence of both a direction main effect $(F=0.70 ; \mathrm{df}=3$ and $12 ; P=0.5694)$ and a date-direction interaction $(F=1.67 ; \mathrm{df}=15$ and $60 ; P=0.1557)$. Monthly aerial trap counts for $F$. fusca, averaged over the five distances from the Stellaria media inoculum source, resulted in 3, 20, and 28 thrips per trap in April, May, and June, respectively.
Date-distance interaction was significant for the number of $F$. occidentalis captured per trap $(F=1.88$; df $=20$ and $60 ; P=$ 0.0314), with few thrips captured during April at any distance but greater numbers captured on traps located nearest to the TSWV inoculum source in May and June. Here again, neither a significant direction main effect $(F=0.23 ; \mathrm{df}=3$ and $12 ; P=0.8729)$ nor a date-direction interaction $(F=0.68$; $\mathrm{df}=15$ and $60 ; P=$ 0.7962 ) was observed. Aerial trap counts for $F$. occidentalis averaged 1, 2, and 13 thrips per trap in April, May, and June, respectively.

In an effort to assess if sources of TSWV outside of our experiment may have had a substantial effect on the incidence of TSWV observed within the experiment, the levels of TSWV infection were estimated in nearby tobacco fields. Incidence of TSWV-infected plants in six tobacco fields within $3 \mathrm{~km}$ of the experiment ranged from 1.3 to $2.9 \%$ and did not vary significantly among fields in June. In July, however, disease levels were higher, ranging from 2.6 to $7.2 \%$ infected plants, and significant differences $(F=4.18$; df $=5$ and $54 ; P=0.0028)$ existed among the six fields surveyed.

\section{DISCUSSION}

Stellaria media, Scleranthus annuus, and Sonchus asper differed greatly in their potential to serve as overwintering hosts for $F$. fusca and sources for subsequent spread of TSWV in spring. Although moderate to low numbers of both adult and immature $F$. fusca were recovered from these three species throughout the winter, populations increased sharply in April and May on Stellaria media and Scleranthus annuus. Populations on Stellaria media reached levels two to threefold higher than on Scleranthus annuus. These results are consistent with previous findings that F. fusca is common on winter annual plants in the winter and early spring in the southeastern United States $(8,12,19)$. Despite the increased mortality observed in Sonchus asper plants, overt symptoms of TSWV infection were not observed in any of the TSWV-inoculated weeds at any time throughout the course of the study.

Previous surveys in North Carolina detected few thrips in soil and litter samples but found substantial reproducing populations of F. fusca, F. occidentalis, and T. tabaci on winter crops and wild hosts (12). Further, Barbour and Brandenburg (1) reported minimal thrips emergence from the soil in newly planted peanut. These results combined with our failure to recover significant numbers of thrips from soil samples strongly suggest that quiescent or diapausing thrips are far less important as sources of TSWV than infected wild plants that support reproducing populations of F. fusca or F. occidentalis throughout the winter and spring.

In addition to differing in suitability as hosts for TSWV vectors, Stellaria media, Scleranthus annuus, and Sonchus asper also differ in suitability as sources of overwintered virus. Both Stellaria media and Scleranthus annuus retained high levels of TSWV throughout the winter and spring. In contrast, levels of TSWV declined dramatically in Sonchus asper in the spring (Fig. 2), and

TABLE 3. Mean \pm standard error number of total Frankliniella fusca and F. occidentalis collected per Stellaria media plant, and proportion of immature $F$. fusca and F. occidentalis that transmitted Tomato spotted wilt virus (TSWV) to petunia leaf disks as adults

\begin{tabular}{|c|c|c|c|c|c|}
\hline \multirow{2}{*}{$\begin{array}{l}\text { Vector species } \\
\% \text { Transmission }\end{array}$} & \multicolumn{5}{|c|}{ Sample date ${ }^{z}$} \\
\hline & January & February & March & April & May \\
\hline F. fusca & $5.1 \pm 1.4 \mathrm{a}$ & $7.5 \pm 2.6 \mathrm{a}$ & $35.6 \pm 11.1 \mathrm{~b}$ & $59.5 \pm 21.6 \mathrm{c}$ & $2.6 \pm 1.4 \mathrm{a}$ \\
\hline$\%$ TSWV & $1.8 \pm 1.2 \mathrm{a}$ & $8.7 \pm 5.1 \mathrm{a}$ & $6.5 \pm 2.9 \mathrm{a}$ & $14.7 \pm 5.7 \mathrm{a}$ & $8.2 \pm 5.5 \mathrm{a}$ \\
\hline F. occidentalis & $1.1 \pm 0.5 \mathrm{a}$ & $3.8 \pm 1.3 \mathrm{a}$ & $15.8 \pm 4.7 \mathrm{~b}$ & $59.5 \pm 12.5 \mathrm{c}$ & $1.2 \pm 0.5 \mathrm{a}$ \\
\hline \% TSWV & $5.0 \pm 5.0 \mathrm{a}$ & $4.2 \pm 2.9 \mathrm{a}$ & $3.8 \pm 1.8 \mathrm{a}$ & $11.6 \pm 3.8 \mathrm{a}$ & $2.9 \pm 2.0 \mathrm{a}$ \\
\hline Transmission & $(N=5)$ & $(N=14)$ & $(N=33)$ & $(N=74)$ & $(N=9)$ \\
\hline
\end{tabular}

${ }^{\mathrm{z}}$ Means within a row followed by the same letter are not significantly different (PROC GLM; LSMEANS) $(\alpha=0.05)$. Optical densities at $405 \mathrm{~nm}$ ranged from 1.633 to 3.082 for TSWV-infected leaf disks and from 0.059 to 0.078 in healthy leaf disks. 
$23 \%$ of Sonchus asper plants infected in the fall died during the experiment. Further, transmission of TSWV by F. fusca developing on these weed hosts during April and May was greatest for Stellaria media (27.4\%), intermediate for Scleranthus annuus (9.3\%), and least for Sonchus asper (1.4\%). Based on these values plus the mean numbers of $F$. fusca per plant in the April and May samples, an estimated 110,15 , and $<1$ viruliferous $F$. fusca per plant were produced from Stellaria media, Scleranthus annuus, and Sonchus asper, respectively. Because these plants were caged and predators were excluded, these estimates may be high. Nonetheless, they clearly show that large numbers of viruliferous thrips can be produced on TSWV-infected winter annual weeds and that the production of viruliferous thrips differs greatly among infected weed species.

Differential susceptibility among vegetative and flowering stages of Stellaria media, Scleranthus annuus, Sonchus asper, and $R$. sardous influences the ability of a weed species to serve as a source for spread of TSWV. Thrips transmission to flowering Stellaria media and Sonchus asper was reduced by $65 \%$ compared with seedling plants, whereas no such reduction was observed in Scleranthus annuus. Similarly, in a greenhouse experiment, thrips transmission to $R$. sardous was $21 \%$ higher in vegetative than flowering stage plants, although transmission to the flowering plants was relatively high $(65.2 \%)$ (Table 2$)$. Typically, these winter annual plants emerge over a prolonged period beginning in early fall. Consequentially, a natural population is composed of plants that mature at different times during the spring and, in some years, early summer. Hence, neighboring plants of the same species may pass through their most TSWV-susceptible stages on different dates. The incidence of TSWV infection would be greatest in those plants that were in the most susceptible stage during flights of viruliferous thrips. In a variable environment, this alone could result in localized patchiness in the incidence of TSWV (6).

In surveys of three common winter annual weed species in Louisiana, only 54 TSWV-ELISA-positive samples (1.6\%) were detected in a sample of 3,348 plants from three locations (19). Similarly, a survey in western Australia detected TSWV infections in $<1 \%$ of 5,543 plants across 24 locations (21), and in Tasmania, TSWV was detected in only $1.5 \%$ of 4,449 plants from two locations (32). In each of these surveys, infected plants were not uniformly distributed spatially, nor were they equally distributed across plant species surveyed; often only one or a few plant

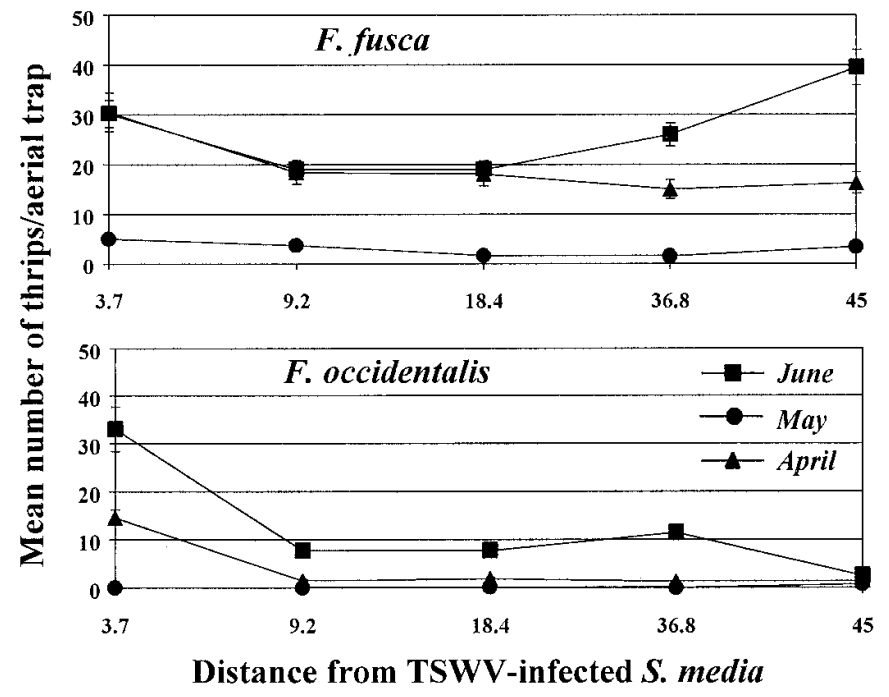

Fig. 6. Aerial trap capture of Frankliniella fusca and F. occidentalis at five distances from the plot center on three sample dates. Mean trap captures not followed by the same letter within months are significantly different by PROC GLM, LSMEANS $(\alpha=0.05)$. species were suggested to account for a majority of the infections. If large numbers of viruliferous thrips were produced on the infected plants, as occurred on Stellaria media in our study, spread of TSWV to nearby susceptible crops could be expected.

In our experiment to observe spread of TSWV from overwintering weeds, spread from Stellaria media occurred in all directions and to the $R$. sardous plots most distant from Stellaria media. In March 1999, the only ELISA-positive $R$. sardous sample occurred $37 \mathrm{~m}$ from the infected Stellaria media source. By April, six newly infected $R$. sardous plots were detected at several distances from the Stellaria media inoculum source. By May, TSWV occurred in $R$. sardous plots at all distances from the inoculum source. Finally, by June, infection levels had increased sharply across all $40 R$. sardous plots. In April and May, there was significantly less infection along paired radians D (171 ${ }^{\circ}$ azimuth) and $E\left(126^{\circ}\right.$ azimuth), which were on the prevailing upwind side of the Stellaria media source plants (Fig. 1). Interestingly, between 1 March and 15 June 1999, approximately 43\% (46 days) of the mean daily wind directions originated from or between these two azimuths (Cunningham Research Station, NOAA ID 4689 , Kinston, NC). The remainder of the time, mean daily wind directions originated along paired radians $\mathrm{F}$ and $\mathrm{G}$ approximately $20 \%$ (21 days) of the time, along paired radians A and $\mathrm{H}$ approximately $16 \%$ (17 days) of the time, and along paired radians B and C approximately $22 \%$ (23 days) of the time.

Although others $(16,32)$ have reported a declining incidence of TSWV infection with distance from an apparent virus source, we observed no such gradients. Both secondary spread within our $R$. sardous plots and the fact that bare ground between plots may have prevented thrips from moving readily among adjacent plots could account for the lack of observed gradients in our experiment. In addition, the interval between samples of our $R$. sardous plots may have been too great to detect rapidly changing gradients. Although, immigrating viruliferous thrips originating from outside of our plot may have contributed to the lack of gradients in our experiment, any such effect is likely to have been limited because the incidence of TSWV infection in neighboring tobacco fields was low $(\leq 5 \%)$ and the spread of TSWV into the $R$. sardous plots coincided with the maturity and senescence of the infected Stellaria media plot.

The spatial pattern of thrips captured on aerial traps located in the $R$. sardous plots is consistent with the dispersal of $F$. fusca and $F$. occidentalis from the TSWV-infected Stellaria media plot. Mean trap collections of $F$. fusca and $F$. occidentalis were low until April, when they began to increase (Fig. 6). In both May and June, capture of $F$. occidentalis was greatest near the inoculum source, suggesting that dispersing western flower thrips probably originated from the infected Stellaria media plants. This gradient was steepest in June, following the senescence of Stellaria media. Captures of $F$. fusca revealed a similar gradient in May, again suggesting dispersal from the Stellaria media plot. However, in June, captures of F. fusca tended to be highest near the Stellaria media plot and the perimeter of the experimental plot, suggesting that $F$. fusca were dispersing from the Stellaria media and into the experimental planting from surrounding vegetation.

Our results clearly demonstrate that weed hosts, such as Stellaria media, can function as overwintering sources of TSWV inoculum, as well as reproductive hosts for vectors that ultimately spread TSWV to other susceptible weed hosts and crops. They further document that the incidence of TSWV-infected weed hosts can increase rapidly during the spring. This increase in the abundance of TSWV inoculum sources occurs before susceptible crops are planted and at a time when vector populations are increasing rapidly. The spread of TSWV among weeds in the spring serves to bridge the period when overwintered inoculum sources decline and susceptible crops are planted. It also creates a situation highly conducive to the spread of TSWV to newly planted susceptible crops. 


\section{ACKNOWLEDGMENTS}

This work was supported, in part, by the North Carolina Agriculture Research Service, and grants from the USDA Southern Region IPM Program (grant 9804380) and the North Carolina Tobacco Commission. We thank C. Berger, C. Ratz, R. Bryan, and V. Covington for technical assistance with both field studies; S. Barnes, Superintendent, Lower Coastal Plain Research Station, Kinston, NC, for implementing the weed control in our Kinston experiment; and H. Coble for donating the smallfield plot.

\section{LITERATURE CITED}

1. Barbour, J. D., and Brandenburg, R. L. 1994. Vernal infusion of thrips into North Carolina peanut fields. J. Econ. Entomol. 87:446-451.

2. Bautista, R., Mau, R. F. L., Cho, J. J., and Custer, D. 1996. Thrips, tospoviruses, and host-plant associations in a Hawaiian farm ecosystem: Prospects for reducing disease losses. Acta Hortic. 431:477-482.

3. Beckham, C. M., Beshear, R. J., and Tippins, H. H. 1971. Some winter host plants of thrips. Univ. Ga. Agric. Exp. Stn. Bull. 86.

4. Best, R. J. 1968. Tomato spotted wilt virus. Adv. Virus Res. 13:65-145.

5. Bond, W. P., Whitam, H. K., and Black, L. L. 1983. Indigenous weeds as reservoirs of tomato spotted wilt virus in Louisiana. (Abstr.) Phytopathology 73:499.

6. Burdon, J. J., Jarosz, A. M., and Kirby, G. C. 1989. Pattern and patchiness in plant-pathogen interactions-causes and consequences. Annu. Rev. Ecol. Syst. 20:119-136.

7. Chamberlin, J. R., Culbreath, A. K., Todd, J. W., and Demski, J. W. 1993. Detection of tomato spotted wilt virus in tobacco thrips (Thysanoptera: Thripidae) overwintering in harvested peanut fields. J. Econ. Entomol. 86:40-45.

8. Chamberlin, J. R., Todd, J. W., Beshear, R. J., Culbreath, A. K., and Demski, J. W. 1992. Overwintering hosts and wingform of thrips, Frankliniella spp., in Georgia (Thysanoptera: Thripidae): Implications for management of spotted wilt disease. Environ. Entomol. 21:121-128.

9. Chambers, W. S., and Sites, R. W.. 1989. Overwintering thrips fauna in croplands of the Texas south plains. Southwest. Entomol. 14:325-328.

10. Cho, J. J., and Mau, R. F. L. 1998. TSWV reservoirs associated with weed hosts found around sugarcane plantations in Maui, Hawaii. Page 103 in: Recent Progress in Tospovirus and Thrips Research. D. Peters and R. Goldbach, eds. International Symposium on Tospoviruses and Thrips in Floral and Vegetable Crops, 4th. Wageningen, the Netherlands.

11. Cho, J. J., Mau, R. F. L., Gonsalves, D., and Mitchell, W. C. 1986. Reservoir weed hosts of tomato spotted wilt virus. Plant Dis. 70:10141017.

12. Cho, K., Eckel, C. S., Walgenbach, J. F., and Kennedy, G. G. 1995. Overwintering of thrips (Thysanoptera: Thripidae) in North Carolina. Environ. Entomol. 24:58-67.

13. Duffus, J. E. 1971. Role of weeds in the incidence of virus diseases. Annu. Rev. Phytopathol. 9:319-340.

14. DuRant, J. A., Roof, M. E., and Cole, C. L. 1994. Early season incidence of thrips (Thysanoptera) on wheat, cotton, and three wild host plant species in South Carolina. J. Agric. Entomol. 11:61-71.

15. Eckel, C. S., Cho, K., Walgenbach, J. F., Kennedy, G. G., and Moyer, J. W. 1996. Variation in thrips species composition in field crops and implications for tomato spotted wilt epidemiology in North Carolina.
Entomol. Exp. Appl. 78:19-29.

16. Gitaitis, R. D., Dowler, C. C., and Chalfant, R. B. 1998. Epidemiology of tomato spotted wilt in pepper and tomato in southern Georgia. Plant Dis. 82:752-756.

17. Greenough, D. R., Black, L. L., Story, R. N., Newsom, L. D., and Bond, W. P. 1985. Occurrence of Frankliniella occidentalis in Louisiana: A possible cause for the increased incidence of tomato spotted wilt virus. (Abstr.) Phytopathology 75:1362.

18. Hagan, A. K., Weeks, J. R., French, J. C., Gudauskus, R. T., Mullen, J. M., Gazaway, W. W., and Shelby, R. 1990. Tomato spotted wilt virus in peanut in Alabama. Plant Dis. 74:615.

19. Johnson, R. R., Black, L. L., Hobbs, H. A., Valverde, R. A., Story, R. N., and Bond, W. P. 1995. Association of Frankliniella fusca and three winter weeds with tomato spotted wilt virus in Louisiana. Plant Dis. 79:572-576.

20. Kaminska, M., and Korbin, M. 1994. New natural hosts of tomato spotted wilt virus. Acta Hortic. 377:123-128.

21. Latham, L. J., and Jones, R. A. C. 1997. Occurrence of tomato spotted wilt tospovirus in native flora, weeds, and horticultural crops. Aust. J. Agric. Res. 48:359-369.

22. Lewis, T. 1997. Flight and dispersal. Pages 175-196 in: Thrips as Crop Pests. T. Lewis, ed. CAB International, Oxon, U.K

23. Mound, L. A. 1996. The Thysanoptera vector species of Tospoviruses. Acta Hortic. 431:298-309.

24. Newsom, L. D., Roussel, J. S., and Smith, C. E. 1953. The tobacco thrips, its seasonal history and status as a cotton pest. La. Agric. Exp. Stn. Tech. Bull. 474.

25. Peters, D. 1998. An updated list of plant species susceptible to tospoviruses. Pages 107-110 in: Recent Progress in Tospovirus and Thrips Research. D. Peters and R. Goldbach, eds. International Symposium on Tospoviruses and Thrips in Floral and Vegetable Crops, 4th. Wageningen, the Netherlands.

26. Salguero Navas, V. E., Funderburk, J. E., Beshear, R. J., Olson, S. M., and Mack, T. P. 1991. Seasonal patterns of Frankliniella spp. (Thysanoptera: Thripidae) in tomato flowers. J. Econ. Entomol. 84:18181822.

27. Stewart, J. W., Cole, C., and Lummus, P. 1989. Winter survey of thrips (Thysanoptera: Thripidae) from certain suspected and confirmed hosts of tomato spotted wilt virus in South Texas. J. Entomol. Sci. 4:392-401.

28. Stobbs, L. W., Broadbent, A. B., Allen, W. R., and Stirling, A. L. 1992. Transmission of tomato spotted wilt virus by the western flower thrips to weeds and native plants found in southern Ontario. Plant Dis. 76:23-29.

29. Toapanta, M., Funderburk, J., Webb, S., Chellemi, D., and Tsai, J. 1996. Abundance of Frankliniella spp. (Thysanoptera: Thripidae) on winter and spring host plants. Environ. Entomol. 25:793-800.

30. Weeks, J. R., French, J. C., and Hagan, A. K. 1990. Virus vectoring thrips common in Alabama peanut fields. Ala. Agric. Exp. Stn. Agric. Res. 37:9.

31. Wijkamp, I., and Peters, D. 1993. Determination of the median latent period of two tospoviruses in Frankliniella occidentalis, using a novel leaf disk assay. Phytopathology 83:986-991.

32. Wilson, C. R. 1998. Incidence of weed reservoirs and vectors of tomato spotted wilt tospovirus on southern Tasmanian lettuce farms. Plant Pathol. 47:171-176.

33. Yudin, L. S., Cho, J. J., and Mitchell, W. C. 1986. Host range of western flower thrips, Frankliniella occidentalis (Thysanoptera: Thripidae), with special reference to Leucaena glauca. Environ. Entomol. 15:1292-1295. 